\title{
Serebral palside ortopedik klinik bakı ve testler
}

\section{Orthopedic clinical examination and tests in cerebral palsy}

\author{
Hüseyin Günay \\ Ege Üniversitesi Tıp Fakültesi, Ortopedi ve Travmatoloji Anabilim Dalı, İzmir
}

\begin{abstract}
Serebral palsili olgularda gelişen motor kayıp ve kas tonusu değişiklikleri, kalça, diz ve ayak olmak üzere hareket sistemini önemli şekilde etkilemekte ve fonksiyonel yetersizliklere yol açmaktadır. Etkilenen kas yapılarının ve eklemlerin tanısının zamanında konulması, kaybolan bazı fonksiyonların bir kısmını zamanla geri kazanmamızı sağlayabilmektedir. Bu olgularda iyi ve etkin bir fizik muayene yardımı ile deformitelere neden olan yapılar ortaya konulabilir. Bu sayede, hastalığın süreci hakkında ön bilgi edinmek ve gelişmesi olası sorunları engellemek mümkündür.
\end{abstract}

Anahtar sözcükler: serebral palsi; fizik bakı; tanı
In patients with cerebral palsy, motor loss and changes in muscle tonus significantly affect the movement system including hip, knee, and foot, and cause functional deficiencies. Timely diagnosis of the affected muscle structures and joints can enable us to recover some of the functions lost over time. Well done physical examination could provide us knowledge of the main pattern causing these deformities. In this way, it is possible to collect information about the process of the disease, and prevent potential problems.

Key words: cerebral palsy; physical examination; diagnosis erebral palsi (SP), gelişmekte olan santral sinir sisteminde meydana gelen bir veya birkaç lezyona bağlı olarak motor işlev kaybına yol açan bir hastalıktır. Oluşan motor işlev bozukluğu yaş ile birlikte değişkenlik göstererek kas-iskelet sistemini de etkiler. Kas tonusunda artış veya azalma yönündeki değişkenlikler, ilerleyen yaş ile birlikte eklemlerde ve kemiklerde yapısal değişikliğe/bozukluğa yol açar. Kas-iskelet sistemi değerlendirmesi yedi ana başlıkta yapılır (Tablo 1 ).

Ortopedik açıdan, erken dönemde kas gücü ve tonusun değerlendirilmesi sonucu yapılan girişimler, ilerleyen zamanlarda oluşabilecek eklem kontraktürleri ve rotasyonel deformiteleri engelleme veya minimuma indirme açısından da önem teşkil eder. ${ }^{[1]}$

Kas gücü değerlendirmesi sıklıkla manuel olarak yapılabildiği gibi dinamometre yardımı ile ya da gelişmiş yürüme analiz laboratuvarlarında izokinetik olarak da yapilır.

Kas tonusunu değerlendirmek, özellikle cerrahi uygulanılacak olgularda çok önemlidir. Hipotonik, distonik veya atetoik tipteki SP'lerde cerrahi işlemler oldukça sınırlıdır. Ortopedik girişimlerin çoğunu spastik tipteki olgular oluşturmaktadır. Spastisitenin değerlendirilmesinde en sık kullanılan yöntem Ashworth skalasıdır. Bu skalaya göre, tonus artışının olmaması 0 puan iken, etkilenen bölgede fleksiyon ve ekstansiyonun olmaması veya hiç hareket yapılamaması eklemin sert (rijid) olduğu anlamına gelir ve 4 puan olarak değerlendirilir. ${ }^{[2]}$

Kas tonusu değerlendirmesi, eklem hareket açıklığı ile birlikte her bölge için ayrı ayrı değerlendirilerek not edilmelidir. Bu yazıda, sıklıkla etkilenen eklem ve kas grupları için belirtilmiş muayene yöntemlerinden bahsedilecektir.

\section{ALT EKSTREMITE}

\section{Kalça}

SP'li olgularda ortopedik muayenenin en önemli kısmını oluşturan eklem grubu kalça eklemidir. Erken dönemde müdahale edilmediği takdirde kalça çevresindeki

- İletişim adresi: Uzm. Dr. Hüseyin Günay, Ege Üniversitesi Tıp Fakültesi, Ortopedi ve Travmatoloji Anabilim Dalı, İzmir Tel: 0533 - 3277068 e-posta: drgunayh@yahoo.com.tr

- Geliş tarihi: 1 Ekim $2018 \quad$ Kabul tarihi: 1 Ekim 2018 
Tablo 1. Serebral palside kas-iskelet sistemi değerlendirme kriterleri
1- Kas gücü değerlendirilmesi
2- Kas tonusu tipi ve derecesi
3- Eklem kontraktürleri
4- Torsiyonel kemik deformiteleri
5- Ayak deformiteleri (sabit-hareketli)
6- Denge
7- Yürümenin değerlendirilmesi

spastisiteler kalça çıkığına neden olur. ${ }^{[3]}$ Bu dönemde uygulanabilecek yumuşak doku cerrahileri, kalçada çıkık veya subluksasyon gelişmesini engelleyici olacaktır. SP'li kalça ekleminde sıklıkla görülen sorunlar; aşırı fleksiyon, adduksiyon ve femoral anteversiyon deformiteleridir. Bu gibi sorunları ortaya koymak için tanımlanmış muayene yöntemleri vardır.

\section{Thomas testi}

Kalça fleksör kas grubundaki, özellikle iliopsoas kasındaki spastisiteyi değerlendirmek amacı ile yapılan bir testtir. Hasta muayene masasında supin pozisyonda yatarken, lomber omurga sabitlenerek değerlendirilir. Tek kalça pasif olarak fleksiyona getirilirken, diğer kalçanın fleksiyonuna bakılır. Fleksör kas grubunda spastisite yok ise diğer kalçanın fleksiyona gelmesi beklenmez. Spastisite varlığında karşı kalçanın da fleksiyona geldiği görülür. Thomas testinin pozitif olduğu spastik hastalarda, yürüyüş esnasında gövde ve kalça fleksiyonda, öne eğilerek yürüyüşe neden olduğundan iliopsoas kasının uzatılması gereklidir (Şekil 1).

\section{Staheli testi}

Bu test, kalça fleksör kas grubundaki ve eklemdeki kontraktürü değerlendirmek için uygulanır. Hasta yüzüstü pozisyonda muayene masasına yatırilır. Alt ekstremite kalça ekleminden itibaren boşta kalacak şekilde masadan sarkıtılır. Tek elle pelvis sabitlenirken diğer el ile kalça ekstansiyona getirilir. Femur aksının yer ile yaptığı açı kontraktür derecesini ve kasın spastisitesini gösterir (Şekil 2).

\section{Duncan-Ely testi}

Kalça fleksör kas grubundan rektus kas grubunun değerlendirmesi için uygulanan bir testtir. Rektus kası kalçaya fleksiyon, dize ekstansiyon yapan bir kastır. Hasta yüzüstü pozisyonda yatarken tek el ile kalça sabitlenir. Diğer el ile dize ani fleksiyon yaparken

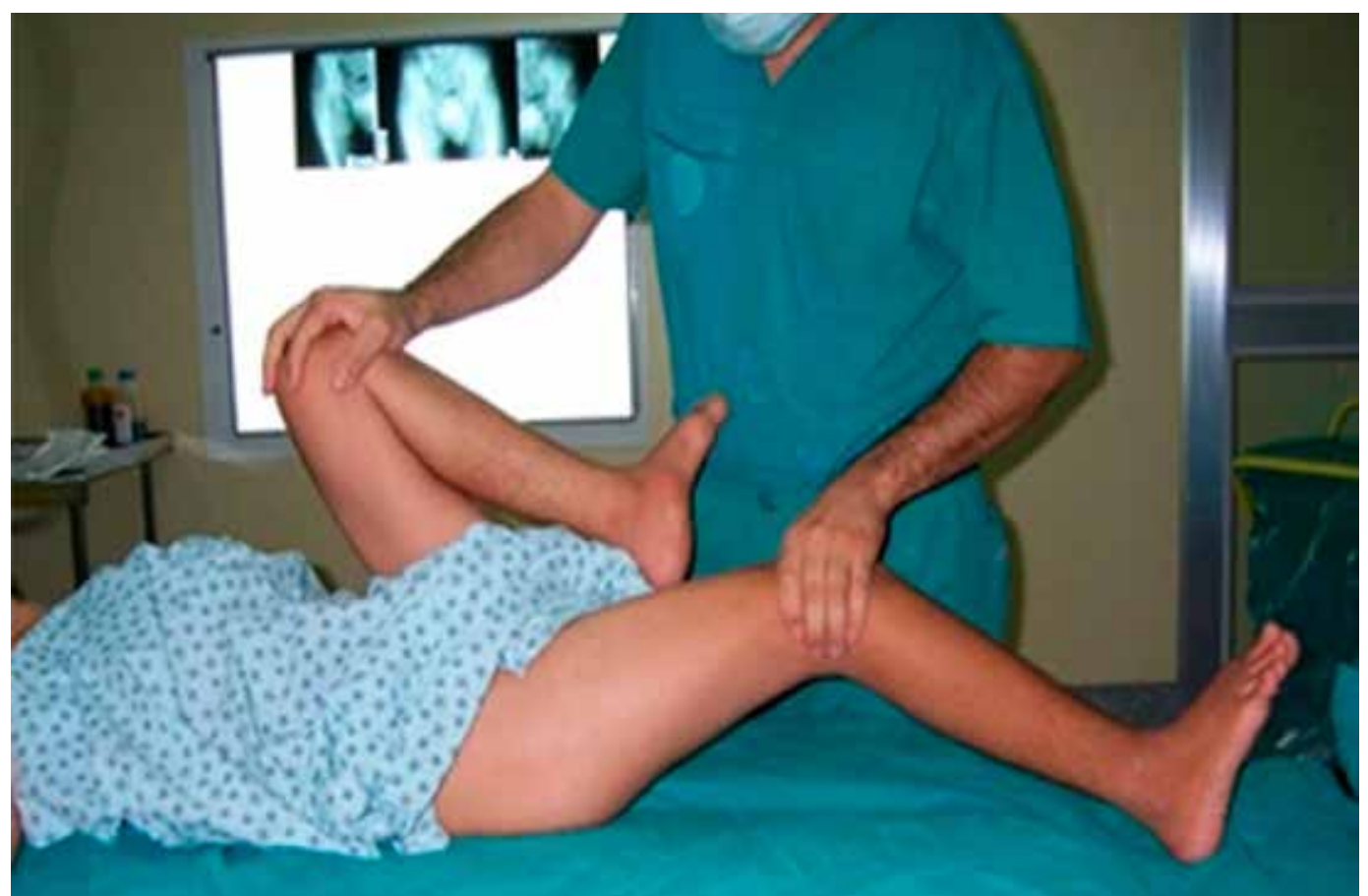

Şekil 1. Kalça fleksör kas grubunu değerlendiren Thomas testi. 


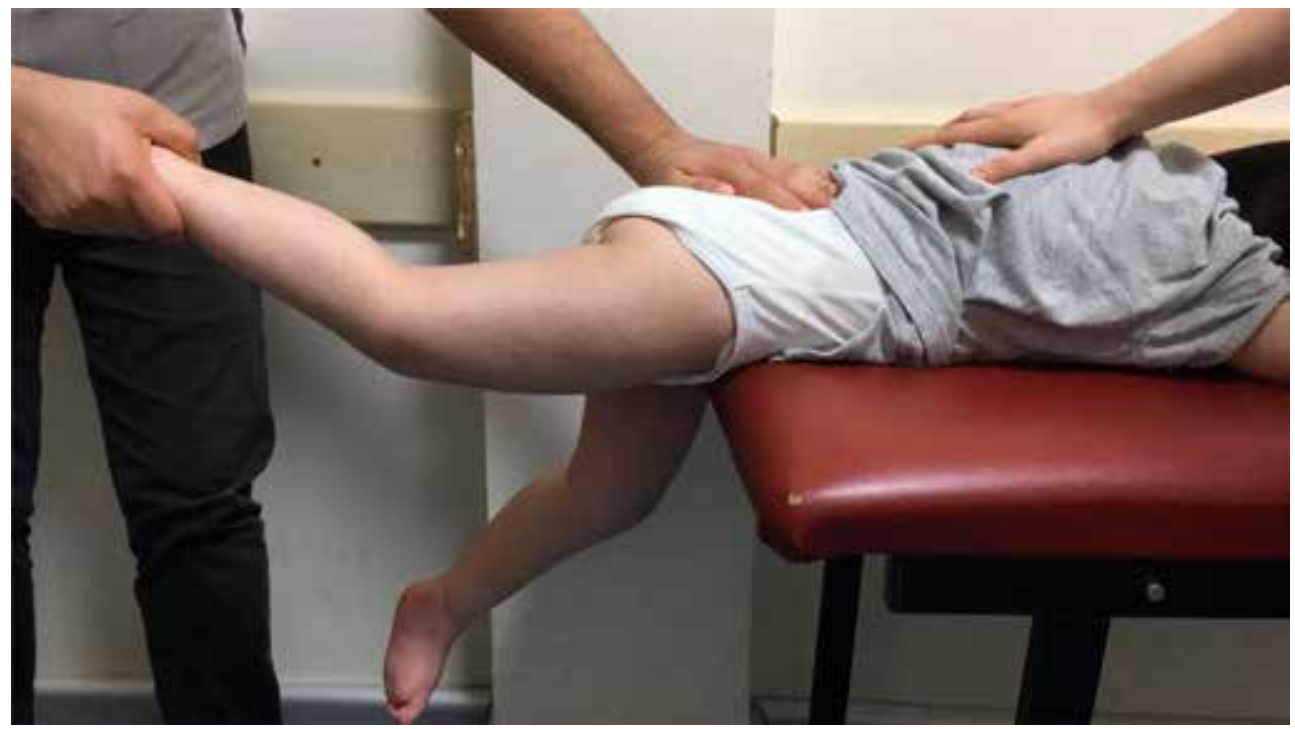

Şekil 2. Kalça kontraktürü değerlendirmesinde Staheli testi.

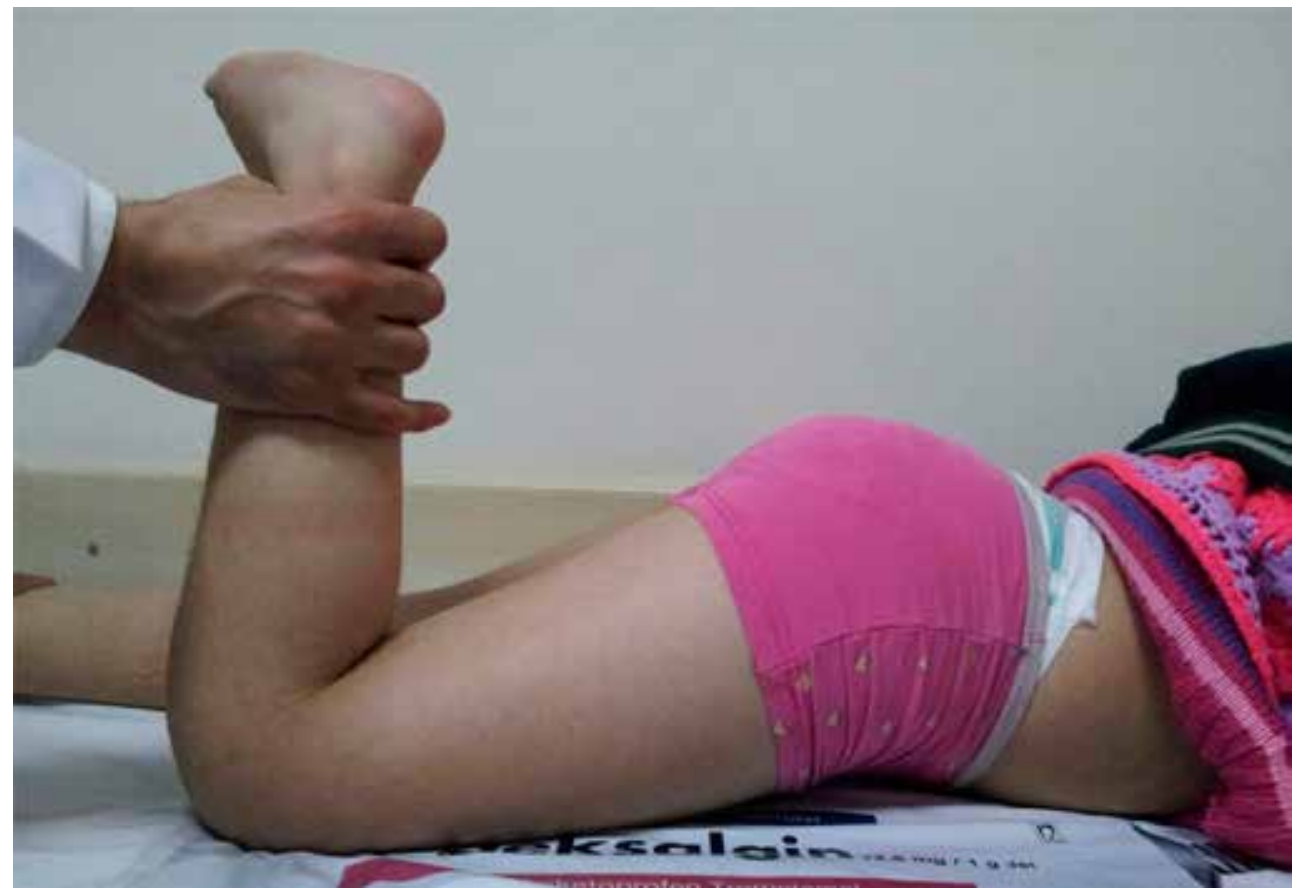

Şekil 3. Rektus, kuadriseps kas grubu değerlendirilmesinde Duncan-Ely testi.

kalçanın ve o tarafta pelvisin muayene masasından yukarı doğru hareket etmesi, rektus kas tonusunun artmış olduğunu gösterir. Yürüyebilen çocukta, bu kasın gerginliği veya tonus artışı dizde fleksiyon azalmasına yol açtığından dolayı, sert diz yürüyüşüne neden olur. Duncan-Ely testinin pozitif olması durumunda ve sert diz yürüyüşü varlığında rektus kasının uzatılması ya da transferi gerekebilir (Şekil 3).

\section{Adduktor spastisite değerlendirmesi}

Kalçalar fleksiyonda ve ekstansiyonda iken değerlendirilmelidir. Grasilis kası, hem kalça hem diz eklemi ile ilişkili biartiküler bir kastır. Diğer adduktor kaslar ise (magnus, longus ve brevis) sadece kalça eklemi ile ilişkilidir (monoartiküler). Diz fleksiyonda iken kısıtılık ortadan kalkıyorsa, sorumlu kas grubunun mediyal hamstring ve grasilis kası olduğu 


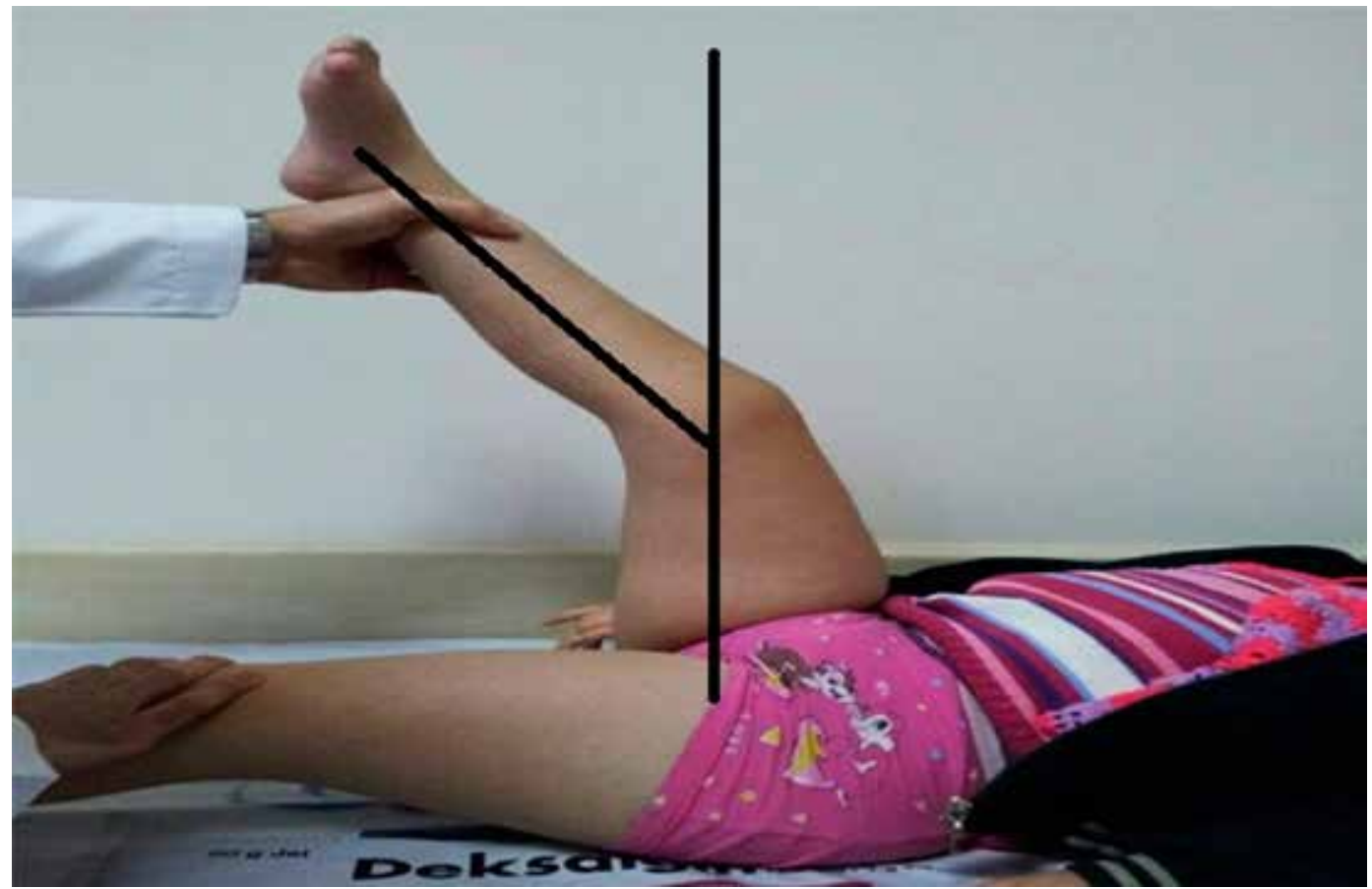

Şekil 4. Popliteal açı ölçümü (Holt yöntemi).

anlaşılır. Hem fleksiyon, hem ekstansiyonda kısıtlılık olması problemin adduktor kaslardan olduğunu gösterir. Adduktor kaslardaki gerginliğin ilerleyen yaşlarda hem rotasyonel problemlere, hem de koksa valgaya ve kalça çıkığına yol açabileceği unutulmamalıdır. Medikal ve fizik tedaviye rağmen ortadan kaldırılamayan spastik adduktor kaslarda gevşetme yapılması gereklidir.

\section{Anteversiyon değerlendirmesi}

Femoral anteversiyon terimi, transvers planda femur başı ile kondiller arasındaki açıyı göstermektedir. Normal bireylerde $15^{\circ}$ civarındadır. Doğumda $45^{\circ}$ olan açı yaş ile birlikte normale dönme eğilimindedir. SP'li çocuklarda, kalça bölgesinde bozulmuş kas tonusunun etkisi ile normal açıya dönüş engellenir. Yüksek derecelerdeki anteversiyon açısı, çocukluk çağında önemli bir içe basma (toe-in) nedenidir. İçe basmanın femur kaynaklı olduğunu anlamada, yürüyüş esnasında patellaların durumuna bakmak bize ipucu verir. Anteversiyon artışına bağlı yürüyüş bozukluklarında patellalar birbirine bakar ve bazen temas edebilir (öpüşen patella). Açı, fizik muayene esnasında kalçalara iç-dış rotasyon yaparak değerlendirilir. Yüzüstü yatar pozisyonda kalçanın aşıı internal rotasyona geliyor olması anteversiyon artışını gösterir. Craig testi bu konuda bize yardımcı olur. Diz $90^{\circ}$ fleksiyonda, kalça ekstansiyonda iken testi yapan kişi sol el ile büyük trokanteri palpe eder, sağ el ile kalça iç rotasyona getirilir. Trokanterin en çıkıntılı olduğu noktada tibia ile arasındaki gonyometre ile ölçülen vertikal açı anteversiyon derecesini verir. ${ }^{[4]}$ Rotasyonel deformite çocukta belirgin yürüyüş bozukluğuna neden oluyor ise femoral rotasyon ostetotomileri gereklidir.

\section{Diz}

SP'li olgularda, dizdeki fleksiyon deformitesine bağlı sıklıkla çömelme yürüyüşü ile karşılaşılır. Bunun dışında, ekstansiyon kontraktürü, genu rekürvatum ve tam ekstansiyon kaybı ile de karşılaşılabilir.

\section{Fleksiyon deformitesi}

Fleksiyon deformitesi, sabit veya fonksiyonel olarak karşımıza çıkar. Sabit deformiteden hamstring kaslarındaki spastisite sorumludur ve bu durum popliteal açı ölçümü ile belirlenebilir. Hasta sırt üstü yatarken, diz ve kalça $90^{\circ}$ fleksiyonda değerlendirilir. Diz eklemi bir direnç ile karşılaşıncaya kadar ekstansiyona getirilir. Dik eksen ile arada kalan açı fleksiyon deformitesinin derecesini gösterir (Şekil 4). Bu açının normalde $0-10^{\circ}$ arasında olması beklenirken, hamstring spastisitesi olan SP'lilerde açının $20^{\circ}$ 'nin üstünde 


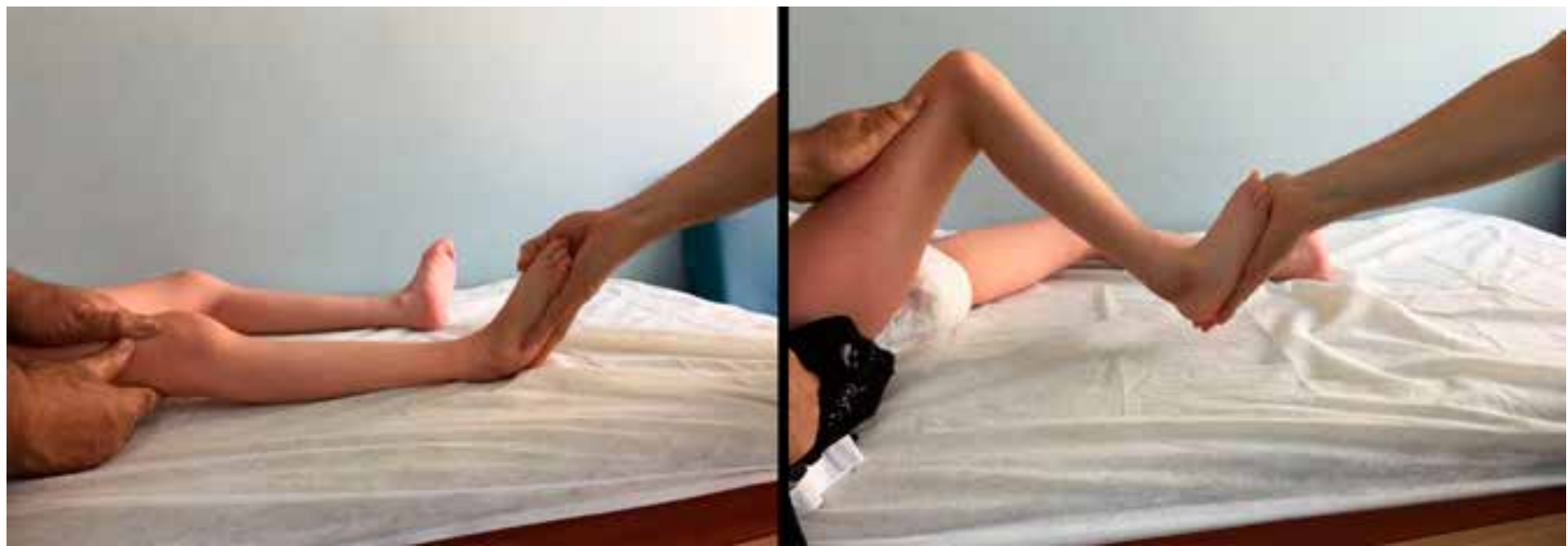

Şekil 5. Ekinusa neden olan kas grubunu değerlendirmede Silverskiöld testi.

olduğu görülür. ${ }^{[5]}$ Daha az sıklıkla, sabit fleksiyon deformitesi, kalça fleksiyon kontraktürü veya ayak bileği ekinus deformitesine kompansatuvar olarak da karşımıza çıkabilir.

Fonksiyonel deformite ise aşırı Aşil tendonu uzatılmasına bağlı ağılık merkezindeki dengesizlik sonucu görülebilir. Nadiren de patellar tendon uzaması kuadriseps kasında yetmezliğe yol açarak fleksiyon deformitesine neden olur.

Bu deformite, yürüme esnasında bükük veya çömelme yürüyüşüne neden olduğundan ve genelde ilk göze çarpan deformite olması nedeniyle oldukça sık cerrahi tedavi uygulanır. Bükük dize cerrahi uygulanmadan önce mutlaka kalça ve ayak eklemleri değerlendirilmeli, izole olarak hamstring deformitesi olduğundan emin olduktan sonra cerrahi işlemler yapılmalıdır. Aksi takdirde yapılan cerrahiler, diz ekleminde iyatrojenik, geri dönüşü olanaksız rekurvatum ve benzeri deformitelere yol açabilir.

\section{Ekstansiyon deformitesi}

Sert diz (stiff knee) olarak adlandırılır; iki nedeni vardır. Kuadriseps spastisitesi veya ayak bileğindeki plantar fleksiyonun gücünde azalma, ayak ekinizmi nedeni ile olabilir. Hamstringlerin iyatrojenik olarak aşırı uzatılması da neden olabilir.

Vastus intermedius dizin en güçlü ekstansörüdür. Bu kasın gerginliği de Duncan-Ely testi ile değerlendirilir (Şekil 3). Yüzü koyun yatarken, dize pasif fleksiyon yapılır, gergin olan kas proksimaldeki yapışma yerinden pelvisi yukarı doğru kaldırır. Bu test, kuadriseps için yüksek oranda spesifisite gösterir. ${ }^{[6]}$

\section{Genu rekurvarum}

Kuadriseps spastisitesi veya hamstring zayıflığı nedeni ile gelişir. Genelde ekinus yürüyüşü ile birlikte karşımıza çıkar. Tedavisi oldukça zor bir deformitedir. Ekinus eşlik ediyorsa öncelikle bu düzeltilmelidir. İleri derece yürüyüş bozukluğuna neden olduğunda tibia fleksiyon osteotomileri gerekebilir. ${ }^{[7]}$

\section{Ayak}

SP'li olgularda en sık karşılaşılan problemler ayak ve ayak bileği sorunlarıdır. Yürüyüşü ve ortez kullanımını önemli derecede etkileyen deformitelerdir. Fizik muayenesi hem ayakta yüklenme ile hem de yatarak yapılmalıdır. Sıklıkla ekinus, pes planovalgus ve parmak bozuklukları şeklinde görülür.

Ekinus deformitesinin nedeni gastroknemius ve soleus kas grubundaki spastisiteden kaynaklanır. $\mathrm{Bu}$ kaslardaki gerginlik birlikte olabileceği gibi izole gastroknemius gerginliği de söz konusu olabilir. Ayrımı yapmak için Silverskiöld testi kullanılır (Şekil 5). Sırtüstü yatarken, öncelikle diz ekstansiyonda iken ayak bileğine dorsifleksiyon yapılır. Sonrasında aynı işlem diz fleksiyona getirilirken de yapılır. Her iki pozisyonda da ayak bileği dorsifleksiyon açısı değişmiyorsa, gerginlikten her iki kas grubu birlikte sorumlu demektir. Sadece diz ekstansiyonda iken ayak dorsifleksiyonu kısıtlı ise, izole gastroknemius kısalığı olduğu anlamını taşır. ${ }^{[8]}$ Sorunlu kasın uzatılması ekinus problemini ortadan kaldırabilir, fakat gereksiz veya aşırı uzatmanın pes kalkaneus deformitesine yol açacağı unutulmamalıdır. 
Varus veya valgus gibi deformiteler, yürüyen olgularda tedavi gerektirebilir. Yürüyen olgularda, ayakta iken topuk arkasından ve ayak önünden bakılarak topukta varus/valgus varlığı ve ayak önü deformiteleri değerlendirilir. İçe/dışa basarak yürüyen olgularda ayak ilerletme açısının değerlendirilmesi ve tibial torsiyon varlığının ekarte edilmesi gerekir.

Pes planovalgus deformitesi peroneal kasların spastisitesinden kaynaklanır. Hafif düztabanlıktan, belirgin instabiliteye ve yürüyememeye kadar geniş bir yelpaze gösterir. Valgus deformitelerinin beş yaşına kadar ortez ile takip edilmesi, cerrahi gerekirse dokuz yaşından önce yapılmaması önerilir. ${ }^{[9]}$

Planovalgus deformitesine sıklıkla eşlik eden diğer ayak sorunları halluks valgus ve dorsal bunyon problemleridir. Bunlar genel olarak ağrıya neden olmaz, fakat ortez kullanımında kısıtlayıcı olabilir. Ayakkabı modifikasyonları veya eksizyon sorunu giderir. Ağır deformitelerde artrodez seçenektir. ${ }^{[10]}$

\section{ÜST EKSTREMITE}

Üst ekstremite tutulumu olan olgularda eklemlerde sıklıkla fleksiyon deformitesi görülür. Diplejik ve hemiplejik olgularda omuz iç rotasyonu, dirsek ve el bileğinde fleksiyon, önkolda pronasyon ve başparmağın avuç içinde olması şeklinde deformiteler oluşur (Şekil 6).

Üst ekstremitenin değerlendirilmesi için kullanımı fonksiyonel açıdan derecelendiren sınıflamalar ve kılavuzlar mevcuttur. House sınıflaması elde en sık kullanılan fonksiyonel sınıflandırmadır. ${ }^{[11]}$ Buna göre elin fonksiyonel kapasitesi, kötü-iyi veya aktif yardımlı - pasif yardımlı veya yardımsız kullanımı şeklinde dokuz alt grupta incelenir (Tablo 2).

Omuzda sıklıkla pektoral ve subskapular kaslar etkilenir. Adduktorve iç rotator kasların spastisitesi, omuzda içe dönük kontraktüre yol açabilir. Abduksiyon ve dış rotasyon kısıtlıdır. Bu deformite, aksiller bölgede hijyen sorunlarına neden olabilir. İleri aşamalarda omuzda subluksasyon gelişebilir.

Dirsek bölgesinde fleksiyon kontraktürü görülür. Biseps, brakiyoradyalis ve brakiyalis kaslarının spastisitesi bundan sorumludur. Kırk beş dereceden az olan deformiteler önemli bir fonksiyonel kayıp oluşturmaz. Bu deformiteye pronator kas grubu da eklenirse, önkolda pronasyon deformitesi oluşturur. Dirsek fleksiyonu ve pronasyon deformiteli olguların bir kısmında radius başı çıkığı oluşabilir. ${ }^{[12]}$

El bileğindeki fleksör kasların gerginliği nedeniyle, el bileği fleksiyon deformitesi SP'li olgularda en sık gözlenen deformitedir. Fleksör karpi ulnaris etkilenerek,

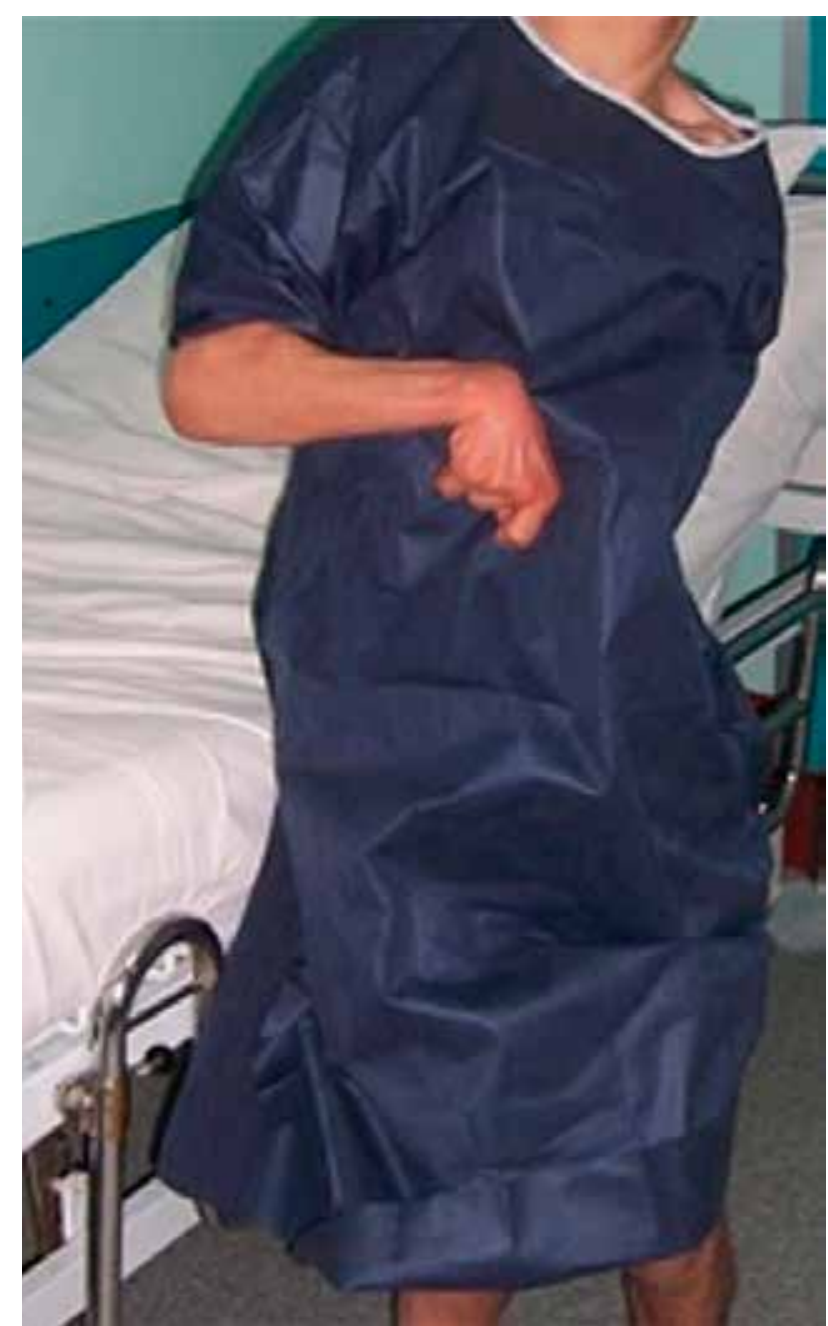

Şekil 6. Diplejik olguda sağ omuz, dirsek, el bileği ve eldeki fleksiyon deformiteleri.

Tablo 2. House üst ekstremite fonksiyonel skorlama sistemi ${ }^{[11]}$

\begin{tabular}{cll}
\hline Düzey & Aktivite şekli & Fonksiyon \\
\hline 0 & Kullanamıyor & Kullanamıyor \\
1 & Pasif, yardımlı, az & Ağır cismi eliyle sabitleyebilir \\
2 & Pasif, yardımlı, orta & Eline verilen cismi tutabilir \\
3 & Pasif, yardımlı, iyi & Eline verilen cismi sabitler \\
4 & Aktif, yardımlı, az & Cismi tutabilir \\
5 & Aktif, yardımlı, orta & Cismi aktif kavrar \\
6 & Aktif, yardımlı, iyi & Cismi aktif kavrar ve iyi tutar \\
7 & Yardımsız kısmen & Diğer elin desteği ile kullanabilir \\
8 & Yardımsız tam & Bağımsız kullanabilir
\end{tabular}


el bileğinin ulnar deviyasyonda durmasına neden olur. Aktif ve pasif olarak el bileği hareket genişliğine bakılmalıdır. Aktif ve pasif olarak hareket kısıtlılığı gözlenen hastaların eklem kapsülünün de kontrakte olduğu akılda tutulmalıdır.

Başparmağın avuç içinde olması (thumb in palm) deformitesi, elin yakalama kavrama fonksiyonlarının kaybına neden olur. Sorumlu çoğunlukla intrensek tenar kaslardaki spastisitedir. Zamanla deformiteye 1. karpometakarpal, metakarpofalengeal ve interfalengeal eklemler de eşlik eder.

Parmaklarda fleksör dijitorum superfisiyalis ve fleksör dijitorum profundus kaslarının gerginliğine bağlı fleksiyon deformitesi, intrensek kas gruplarının etkilerine bağlı olarak da kuğu boynu deformiteleri görülür. El bileğinde fleksiyon kontraktürü olan ve ekstansör zayıflığı olan olgularda, kompanse etmek için parmak ekstansörlerinin aşırı kullanılması hiperekstansiyon deformitelerinin artmasına neden olabilir. ${ }^{[13]}$

\section{KAYNAKLAR}

1. Novacheck TF, Trost JP, Sohrweide S. Examination of the child with cerebral palsy. Orthop Clin North Am 2010;41(4):46988. Crossref

2. Patrick E, Ada L. The Tardieu Scale differentiates contracture from spasticity whereas the Ashworth Scale is confounded by it. Clin Rehabil 2006;20(2):173-82. Crossref

3. Bagg MR, Farber J, Miller F. Long-term follow-up of hip subluxation in cerebral palsy patients. J Pediatr Orthop 1993;13(1):32-6. Crossref
4. Yoon TL, Park KM, Choi SA, Lee JH, Jeong HJ, Cynn HS. A comparison of the reliability of the trochanteric prominence angle test and the alternative method in healthy subjects. Man Ther 2014;19(2):97-101. Crossref

5. Holt KS. Deformity and disability in cerebral palsy. Dev Med Child Neurol 1963;5(6):629-31. Crossref

6. Marks MC, Alexander J, Chambers HG. Clinical utility of the Duncan-Ely test for rectus femoris dysfunction during the swing phase of gait. Dev Med Child Neurol 2003;45(11):7638. Crossref

7. Karol LA. Neuromuscular disorders. In: Herring JA, editor. Tachdjian's Pediatric Orthopaedic. From The Texas Scottish Rite Hospital For Children, 5. ed. Philadelphia, PA: Saunders/ Elsevier; 2012. pp.1285-91.

8. Yalçın S, Berker N, Dormans J, Sussman M. Serebral Palsi Tedavi ve Rehabilitasyonu -Pediatrik Ortopedi Rehabilitasyon Dizisi, 3. baskı. Mas Matbaacılık; 2000.

9. Sees JP, Miller F. Overview of foot deformity management in children with cerebral palsy. J Child Orthop 2013;7(5):373-7. Crossref

10. Çullu E, Çobanoğlu M. Beyin Felcinde ayak, ayak bileği sorunları. İçinde: Hepgüler S, Gökben S, editörler. Serebral Felç, Bölüm 26. İstanbul: Nobel Tıp Kitabevi; 2017. pp.235-41.

11. House JH, Gwathmey FW, Fidler MO. A dynamic approach to the thumb-in palm deformity in cerebral palsy. J Bone Joint Surg Am 1981;63(2):216-25. Crossref

12. Abu-Sneineh AK, Gabos PG, Miller F. Radial head dislocation in children with cerebral palsy. J Pediatr Orthop 2003;23(2):155-8. Crossref

13. Ademoğlu Y, Gürbüz Y. Beyin felcinde üst ekstremite cerrahisi. Içinde: Hepgüler S, Gökben S, editörler. Serebral Felç, Bölüm 22. İstanbul: Nobel Tıp Kitabevi; 2017. pp.195-207. 